\title{
Las cooperativas frente a la crisis
}

\author{
Alejandro Martínez Charterina \\ Catedrático de la Universidad de Deusto, \\ Presidente de la Asociación Internacional de Derecho Cooperativo
}

Recibido: $\quad$ 10.05.10

Aceptado: 02.06 .10

Sumario: Crisis y cooperativas. Las crisis económicas. La crisis actual. Elementos para interpretar la crisis. ¿Qué hacer de cara al futuro? Las cooperativas ante la crisis actual. Conclusiones.

Resumen: Las cooperativas, con carácter general, son más resistentes a la crisis que otras empresas. Tras unas consideraciones generales acerca de las crisis y su contexto, y un repaso de los elementos característicos de la crisis actual, se aborda el estudio del modelo de empresa cooperativa, su actuación frente a la crisis y su capacidad de crecimiento cara al futuro.

Palabras clave: Crisis económica, cooperativas, valores éticos, responsabilidad social.

Abstract: Cooperatives as a whole are more resistant to crisis than other companies. After some general considerations about crises and their context, and a review of the key characteristics of the current crisis, this work examines the cooperative business model, its action plan to tackle crisis and its capacity for future growth.

Key words: Economic crisis, cooperatives, ethical values, social responsibility. 


\section{Crisis y cooperativas}

No es una exageración afirmar que hablar de cooperativas es hablar de crisis. O por lo menos podemos decir que las cooperativas entienden de crisis ${ }^{1}$.

La historia nos muestra que muchas veces las cooperativas han constituido un buen camino de salida de un grupo de personas frente a las situaciones críticas en las que se encontraban. Seguramente la situación que relata Georges J. Holyoake en el origen inmediato de la Cooperativa de Rochdale puede extenderse a muchas de las cooperativas que se formaron en ese entorno temporal de la primera mitad del siglo XIX.

Los tejedores, mal retribuidos, intentaron conseguir sin resultados un aumento de salarios en Rochdale, Manchester, en 1843, cuando la industria textil estaba rindiendo grandes beneficios.

En estas condiciones, "algunos de esos tejedores, sin trabajo, casi sin pan y socialmente aislados por completo, se reunieron para estudiar lo que más convenía hacer», y veintiocho de ellos terminaron por constituir la «Rochdale Society of Equitables Pioneers», la Cooperativa de Rochdale, la que se considera primera cooperativa moderna².

Mucho más cerca, en el tiempo y en el espacio, podemos considerar también el contexto de crisis en el que se encuentra tras la guerra civil española el pueblo de Mondragón al que es destinado como coadjutor de la parroquia D. José M. ${ }^{a}$ Arizmendiarrieta, que inspirará y asistirá hasta su muerte a las cooperativas de Mondragón.

«Los momentos son difíciles; la guerra civil ha dejado a la villa dividida y destruida económicamente. Huelgan retóricas pacifistas y hay imperiosa necesidad de justicia social, de apertura hacia nuevas posiciones de participación e integración social», escribe José María Ormaechea, uno de los cinco fundadores de la primera cooperativa de Mondragón ${ }^{3}$.

Del mismo modo podemos también imaginar orígenes más o menos críticos en las cooperativas que se forman en todos los países subdesarrollados.

En ocasiones las crisis han sido también la causa de que las cooperativas desaparezcan. En los tiempos del comienzo del cooperativismo

1 Johnston Birchall y Lou Hammond Ketilson, Resilience of the cooperative business model in time of crisis (2009), pp. 5 ss. relatan muchos comienzos de cooperativas en tiempos de crisis, lo que no significa, por otra parte, que el éxito de las cooperativas esté unido a la crisis.

2 Georges Jacob Holyoake, Historia de los pioneros de Rochdale (1989), pp. 9 ss.

3 José María Ormaechea, La experiencia cooperativa de Mondragón (1991), p. 31. 
moderno la conocida cooperativa que puso en marcha Michel Derrion en Lyon, en 1835, "Le commerce véridique et socia/», no pudo resistir la grave crisis económica que tuvo lugar en Lyon y su entorno en 1836 y 37, que mermó la capacidad adquisitiva de los trabajadores e hizo descender la actividad de la cooperativa hasta llevarla a su cierre en 1838, a pesar del éxito cosechado en sus comienzos ${ }^{4}$.

No sucedió lo mismo, en cambio, con la Cooperativa de Rochdale que salió airosa de la crisis que se produjo entre las industrias de Manchester durante los años 1861 a 1865 como consecuencia de la falta de materia prima, algodón, cuya producción se vio comprometida por la guerra de secesión entre los Estados del Norte y del Sur (algodoneros) en los Estados Unidos de América. Los trabajadores estaban desempleados, pero en los cuatro años subieron las ventas del almacén y el número de socios 5 .

En la actualidad, entre 2004 y 2008 descendieron un 2\% las cooperativas en España, si bien aumentó el empleo de las mismas en un $1 \%{ }^{6}$.

Por otra parte, además de las crisis externas, no escapan las cooperativas a sus propias crisis internas. Alex F. Laidlaw en el informe «Las cooperativas en el año 2000», presentado al XXVII Congreso de la Alianza Cooperativa Internacional, celebrado en Moscú en 1980, que constituirá el punto de partida de la reflexión profunda que acometió el cooperativismo mundial para abordar el estudio de los valores y principios cooperativos que se aprobaron en el Congreso Centenario de la Alianza en 1995, con los que se trató de encarar el nuevo milenio, al fijarse en la historia de las cooperativas detecta tres etapas de cambio a partir de las crisis que las cooperativas han desencadenado y superado, logrando su propio crecimiento tras cada una de ellas:

Se trata en primer lugar de una crisis de credibilidad de que las cooperativas podían ser y sobrevivir, propia de los primeros tiempos del cooperativismo moderno; de aquí también la falta y el retraso de legislaciones específicas en muchos lugares.

Superada esa primera crisis, se refiere, en segundo lugar, una crisis administrativa, en la medida en que son muchos los fracasos y los cierres de cooperativas, pero también llegó el tiempo del asentamiento, de la gestión competente y se superó esa crisis.

Por fin, se define la crisis presente, del tiempo del informe, como crisis ideológica. La cooperativa está asentada como empresa y desem-

4 Denis Bayon, Le commerce véridique et social de Michel-Marie Derrion. Lyon, 1835-1838 (2002), p. 24.

5 Georges Jacob Holyoake, o. c., capítulo XII, pp. 69 ss.

6 La Economía Social en España 2008/2009 (2009), p. 25. 
peña bien sus funciones. Sin embargo, no basta ser como las demás empresas, hay un sistema de comportamiento a través del que las cooperativas deben actuar?

En el mismo sentido, en otra parte del Informe, llega a decir: «En época tan crucial como esta, las cooperativas deben tratar de mantenerse como islas de cordura en un mundo que se está volviendo loco»8.

De esa crisis se saldrá con la «Declaración de la Alianza Cooperativa Internacional sobre la identidad cooperativa», que se aprobó en el XXXI Congreso de la Alianza, celebrado en Manchester en 1995, año de su centenario, que revisará los principios cooperativos e introducirá los valores cooperativos para conformar la identidad cooperativa.

\section{Las crisis económicas}

Las crisis económicas se insertan en los ciclos económicos. Estos son «movimientos de ritmos y duración distintos, de características distintas, que constituyen una evolución alternante»?.

Antes del proceso de industrialización los ciclos venían marcados sobre todo por circunstancias naturales que afectaban a las cosechas e incidían en los precios en un ámbito de referencia local. Con la industrialización y la extensión del comercio internacional pasaron a depender de la demanda y a transmitirse a través del comercio de unos a otros países ${ }^{10}$.

Entre los tipos de ciclo aceptados, el ciclo medio o de Jutglar es el que se conoce como ciclo económico y es en el que se insertan las crisis económicas. Las fases del ciclo completo son el comienzo de la expansión o recuperación, la expansión que conlleva el aumento de la actividad, la depresión con descenso del crédito, caída de la bolsa, etc. y la contracción en la que aparecen los procedimientos concursales y la reducción de empleo.

En este ciclo la crisis económica se sitúa en el lugar de paso de la expansión a la depresión ${ }^{11}$. Aunque en muchas ocasiones se habla indistintamente de crisis y de depresión, la crisis se refiere al comienzo de cambio de la tendencia, al principio del descenso del ciclo, donde

7 A.F. Laidlaw, «Las cooperativas en el año 2000», en Tribuna Cooperativa, n. os 4445 (1982), pp. 16 y 17.

8 A.F. Laidlaw, O. c., p. 25.

9 Valentín Vázquez de Prada, Historia económica mundial, tomo II (1970), p. 153.

10 Rondo Cameron: Historia económica mundial (2000), p. 390.

11 Valentín Vázquez de Prada, o. c., p. 154. 
ya aparece el descenso de la actividad, del comercio y el paro, mientras que la depresión se sitúa en la parte baja del ciclo, más general y duradera que la primera.

La historia económica ha recogido la existencia de muchas crisis económicas, de diversa índole e importancia ${ }^{12}$. Rocojo unas anotaciones de algunas de ellas.

En primer lugar la conocida como crisis de los tulipanes. Nos muestra un modelo de la formación de una burbuja hasta su explosión, que ayuda a comprender la situación de crisis actual ${ }^{13}$.

Los tulipanes llegaron a Europa occidental procedentes de Turquía en la segunda mitad del siglo XVI y destacaron por su colorido y sus distintas variedades, de forma que las familias acomodadas holandesas pagaban grandes sumas de dinero por obtenerlos llegando incluso a enviar a comprar los bulbos directamente a Constantinopla ${ }^{14}$.

La pasión por los tulipanes hizo que en las ciudades importantes se formaran bolsas de tulipanes y en los pueblos la taberna sirviera para esos mismos menesteres, y entrado el siglo XVII, hacia 1834, el afán por conseguir cada vez más tulipanes llevó a que los precios aumentaran sin descanso, llegándose a considerar que «cuanto más subían los precios de los bulbos, más personas empezaban a considerarlos una inversión inteligente» ${ }^{15}$.

El gusto dio paso a la especulación y en tal contexto se relatan casos de personas que cambiaron su casa por los preciados bulbos. Del mismo modo llama la atención las confusiones de los bulbos de tulipán con cebollas que llevaron a comerlos o a trocearlos y enviaron a la cárcel a los que cometieron tal confusión.

De este modo fue creciendo la burbuja durante años hasta que, habiendo llegado a precios disparatados, explotó en 1837. Charles Mackay lo recoge en esta cita: «Por fin, sin embargo, los más prudentes comenzaron a ver que esta locura no podía durar para siempre. Los ricos no compraban más las flores para tenerlas en sus jardines sino para venderlas con un beneficio del cien por cien. Se vio que alguno debía perder terriblemente al final. A medida de que esta convicción se extendía los precios cayeron y nunca subieron de nuevo. Se destruyó la

12 Oriol Amat, Euforia y pánico (2009), pp. 17 y 18, recoge una selección de 42 cracks.

13 Cuentan esta crisis de los tulipanes Oriol Amat, o. C., pp. 19 ss., y Carlos Salas, La crisis explicada a sus víctimas (2009), pp. 223 ss.

14 Charles Mackay, Memoirs of Extraordinary Popular Delusions and the Madness of Crowds (1852), Cap. 3.1.

15 Burton Malkiel, Un paseo aleatorio por Wall Street (1999), citado por Carlos Salas, o. c., p. 223. 
confianza, y un pánico universal embargó a los vendedores. A había acordado comprar diez Sempers Augustines (una variedad de tulipanes) a $\boldsymbol{B}$, por cuatro mil florines cada uno seis semanas después de la firma del contrato. B estuvo preparado con las flores a su debido tiempo, pero el precio había caído a tres o cuatrocientos florines y $\boldsymbol{A}$ se negaba a pagar la diferencia o a recibir los tulipanes... $»^{16}$. Mackay bautizó el fenómeno como tulipomanía ${ }^{17}$.

Oriol Amat destaca acertadamente los elementos presentes en los comportamientos que se observan en esta crisis de los tulipanes. En ellos hay ambición, soberbia, envidia, ceguera, miedo, pánico, histeria, endeudamiento abundante y riesgo correspondiente, falta de realismo en la valoración, utilización de instrumentos derivados ${ }^{18}$.

A pesar de la distancia temporal esas características resultan familiares en otros momentos históricos y también en los tiempos presentes.

Ya en la era industrial las crisis financieras seguidas de depresiones fueron abundantes. Entre ellas destaca la que se conoció, hasta que llegó la crisis del 29, como Gran Depresión tras la crisis de 1873. Esta se produjo, después de unos años de expansión, por la caída de las Bolsas de Viena y Nueva York, y se extendió con rapidez por los países industrializados y que se estaban industrializando ${ }^{19}$.

Fue la más importante y extensa hasta entonces, y, en la medida en que muchos culparon al comercio internacional, que se había desarrollado muy notablemente a partir del Tratado Cobden-Chevallier de $1860^{20}$, algunos países volvieron a las políticas proteccionistas retrasando el crecimiento del mismo hasta el final del siglo.

La crisis del 29 pasó a ser la crisis por antonomasia. Salidos de la Primera Guerra Mundial, la Gran Guerra, y habiendo comenzado un periodo de relativa prosperidad en algunos países, los felices años veinte, la crisis vendrá a sacudir de nuevo las economías y prolongará los efectos de la depresión durante muchos años, en la práctica hasta la Segunda Guerra Mundial21.

16 Charles Malkiel, o. c., Cap. 3.8.

17 The Tulipomania es el título del capítulo 3 de su obra en el que relata el caso.

18 Oriol Amat, o. c., pp. 20 y 21.

19 Rondo Cameron, o. c., pp. 390-391.

20 El Tratado Cobden-Chevallier, firmado en 1860 entre Francia y Gran Bretaña, eliminaba muchos aranceles y reducía los correspondientes a los pocos productos para los que se mantenían, incorporando, además, la cláusula de la nación más favorecida, por lo que, al ser imitado por otros muchos acuerdos internacionales, hizo avanzar decididamente el librecambio y el comercio internacional a partir de entonces.

21 Los Estados Unidos, que tenían 15 millones de parados en 1933, llegaron a la Segunda Guerra Mundial en 1941 con 6 millones de parados todavía. 
Tras la Primera Guerra Mundial Los Estados Unidos quedaron muy fortalecidos, sin daños en su territorio y con una capacidad de producción agrícola e industrial extraordinaria y en situación acreedora. A pesar del ensanchamiento de sus mercados y de su capacidad financiera, se extendió la venta a crédito, se fueron produciendo grandes excedentes, e hicieron bajar los precios.

Las inversiones en ese periodo de prosperidad se habían dirigido a la Bolsa de Nueva York, y los múltiples bancos existentes prestaban en abundancia para adquirir acciones sin otra garantía que los propios títulos.

El descenso de los precios repercutió en la Bolsa en octubre de 1929 y provocó la venta masiva de acciones, que cayeron del índice 400 a menos de 50, dejando de inmediato muchas personas arruinadas y bancos quebrados 22 .

«Hasta aquél fatídico jueves de octubre (24 de octubre de 1929, el jueves negro) en que los valores de Wall Street se hundieron un 13\%, la palabra que mejor definía la situación de Estados Unidos era prosperity. Pero en realidad era una codicia irracional» 23 .

Selecciono dos anécdotas que cuenta Carlos Salas en este punto. Un húngaro, André Kostolany, se dio cuenta de que la burbuja, que se había formado en la bolsa con apalancamiento a base de compras a crédito y en descubierto, tenía que explotar y decidió hacer lo contrario de lo que hace la mayoría vendiendo cuando todos compraban y comprando cuando todos vendían, con lo que se enriqueció con el crack del 29. La segunda, más dramática, se refiere al señor que fue a un hotel y pidió su habitación en un piso alto; le preguntaron si era para dormir o para saltar24.

La caída de la Bolsa provocó el llamado «efecto dominó», se retiraron los ahorros de los bancos, el crédito se redujo, la demanda se contrajo, quebraron bancos y empresas, el paro se disparó, los salarios bajaron, la demanda se contrajo más...

Se repatriaron las inversiones exteriores y se terminó el crédito a los países europeos, con lo que la crisis se extendió por estos países y se redujo el comercio internacional de modo que los países exportadores recibieron por ese conducto el impacto de la crisis.

Las consecuencias en cuanto a la duración y profundidad de la crisis la juntaron con la Segunda Guerra Mundial. La crisis del 29 hizo que se incrementara la participación del sector público en las economías, dio paso a la política económica keynesiana, ayudó al establecimiento

22 Oriol Amat, o. c., p. 23.

23 Carlos Salas, o. c., p. 228.

24 Carlos Salas, O. c., pp. 227-228. 
de los regímenes políticos extremistas, y su recuerdo ha permanecido vivo hasta nuestros días.

En el proceso de acercamiento al momento presente hay que recordar la crisis del petróleo de 1973. Ésta comenzó por la restricción en la producción de crudo que llevó a cabo la OPEP, que produjo una subida de los precios tal que se multiplicaron por cuatro, al tiempo que los países occidentales dependían casi exclusivamente del petróleo como fuente energética, y se temían una catástrofe para fin de siglo por el agotamiento de los pozos entonces existentes.

En el tiempo siguiente cayeron las bolsas y se produjo la que se llamó estagflación, es decir, estancamiento e inflación simultáneos, o, en determinados casos, recesión con alza de precios, contraviniendo la teoría de Phillips que proponía el control de la inflación con desempleo y el del desempleo con inflación. Al ser el petróleo materia prima principal y producto energético por excelencia, la crisis se extendió con facilidad encareciendo los costes de producción, los transportes, etc.

Las tasas de inflación de dos dígitos resultaban desacostumbradas en las economías occidentales y el desempleo alcanzó tasas también importantes en algunos países (el $25 \%$ de la población activa en el nuestro). Lo novedoso de esta crisis y la falta de diagnóstico certero acerca de sus causas hizo que se siguiera el método de la prueba y el error y que costara salir de ella bastante tiempo a algunos países, aunque otros lo hicieron con más facilidad.

Nuevas crisis del petróleo o rebrotes se producirían en los años ochenta y noventa por las guerras entre países productores (Irak-Irán, e invasión de Kuwait), con efectos bastante menos importantes ${ }^{25}$.

Por fin, la crisis de las empresas de internet, las puntocom, cuyas cotizaciones habían formado una burbuja desde mediados de los años noventa, que explotó en marzo de 2000, provocando la caída de tres de cada cuatro empresas tecnológicas en los cinco años siguientes y reconduciendo el valor bursátil de las supervivientes a menos de la mitad del que tenían entonces ${ }^{26}$.

La especulación llegó a ser tan importante que, a modo de ejemplo, el PER de Yahoo llegó a 508, y en nuestro entorno Terra salió a bolsa por $12 €$ aproximadamente, subió en poco tiempo hasta 150 para caer a $5^{27}$.

25 Sobre la crisis del petróleo puede verse Oriol Amat, o. c., pp. 25-26.

26 Patricia Vargas y Ana Palomares, «Supervivientes.com: Una década después», en El Economista, 10 de marzo de 2010, pp. 32 y 33.

27 PER (price earnin ratio) es el cociente de la cotización de una acción entre el beneficio neto correspondiente a la misma. Un PER de 12 a 14 indica que la acción puede 


\section{La crisis actual}

El origen de la crisis actual se sitúa justamente en el año 2001, tras el estallido de la burbuja de las empresas puntocom, en el que se produjeron los atentados de las torres gemelas y el parón correspondiente de la actividad económica estadounidense ${ }^{28}$.

Para reactivar la economía la Reserva Federal baja el tipo de interés, que estaba en el $6 \%$, y que descenderá al $1 \%$ en dos años, orientándose las inversiones hacia el sector inmobiliario.

Y es aquí donde aparecen los intermediarios, brokers, vendedores de hipotecas, que se acercan a ofrecer créditos a largo plazo, con tiempos de carencia, tras los cuales debían pagar intereses más elevados ${ }^{29}$, cubriendo por encima del $100 \%$ del valor de la propiedad inmobiliaria, sin otra garantía que la hipoteca, a cualquier persona que desee obtener la propiedad, incluidos los llamados ninjas por Leopoldo Abadía, es decir las personas no income, no job, no assets, que no tienen ingresos ni trabajo fijo y que tampoco tienen propiedades ${ }^{30}$.

Esto resulta interesante para los vendedores de hipotecas que cobran comisión por cada una de las que colocan, interesa a los deudores que se convierten en propietarios, siquiera sea de forma temporal, y obtienen dinero por encima del precio de la casa, con lo que también pueden comprar otras cosas adicionales, y a los mismos bancos que multiplican los créditos que conceden y consiguen unos intereses más elevados. Naturalmente, los bancos saben que muchas de las personas a los que conceden sus créditos no podrán pagar la hipoteca, pero como los precios de las viviendas crecen sin cesar, esperan resarcirse al venderlas de nuevo con precios más elevados.

Por otro lado, los bancos, que necesitaban más dinero para poder seguir colocando hipotecas, empaquetarán éstas mezclando las buenas, prime, con las menos buenas, subprime, en las que el riesgo de devolución es mayor, es decir, las concedidas a los ninjas, formando paquetes de productos financieros derivados, creados gracias a la desregulación del sistema financiero, que venden a otros bancos, ya sean

ser cara, por lo que el de 508 es un buen ejemplo de la burbuja. Puede verse en Oriol Amat, o.c., pp. 28 y 29, en la que se ofrece también el gráfico de la evolución del índice NASDAQ

28 Ignacio Ramonet, La catástrofe perfecta (2009), p. 73. También, entre otros, Oriol Amat, o. c., p. 39; Carlos Salas, o. c., 118.

29 Pero eso venía en la letra pequeña... Carlos Salas, citando a Guillermo de la Dehesa, o. c., p. 119.

30 Leopoldo Abadía, La crisis ninja y otros misterios de la economía actual (2009), p. 21. 
de inversión en los Estados Unidos, o cualquier banco en otros países, y en particular, en Europa, y a través de ellos a los inversores ${ }^{31}$.

Esos paquetes son comprados con facilidad porque vienen avalados por las agencias de calificación o de rating, las cuales conceden los máximos niveles de calificación a estos productos, a instancia y pago, eso sí, de los mismos bancos «empaquetadores». Por otra parte, se trata de comprar para volver a vender.

Con ello consiguen obtener más dinero para seguir prestando y trasladar el riesgo a otros.

Interpretándolo desde el lado del dinero, Juan Antonio Melé dice lo siguiente: «... desde entonces (caída del Muro de Berlín) más que antes el dinero circula de forma ficticia y virtual, sin corresponderse con una verdadera creación de riqueza. En consecuencia el beneficio se convirtió en un fin en sí mismo: unos pocos se pusieron a especular a partir de la llamada "ingeniería financiera" para que el dinero creciera por sí mismo y generara más capital sin producir a cambio ningún bien ni servicio. El dinero se hinchó como un globo...» ${ }^{32}$

En esta operación hace una aportación especial una característica particular que acompaña a la economía desde la caída del Muro de Berlín, que es la globalización. Sin ser desconocida antes del acontecimiento señalado, desde entonces su importancia es cada vez mayor, lo que, en el caso de la crisis, hace que ésta se traslade de una economía a otra y que lo haga con mucha rapidez.

Ante el incremento de la demanda y el aumento inflacionista de los precios la Reserva Federal sube el tipo de interés lentamente en Estados Unidos a partir de 2003, tiempo en el que estaba en el $1 \%$, hasta llegar al 5,5\% en 2006, y comienzan las devoluciones de las llaves de las viviendas por no poder pagar las hipotecas ${ }^{33}$.

Y comienza a desinflarse la burbuja inmobiliaria y a caer los precios de las viviendas. En 2007 se empiezan a presentar los daños en pri-

31 Estos derivados financieros son plurales y sofisticados. Entre ellos los llamados MBS, Mortgage Backed Securities, obligaciones garantizadas por hipotecas, CDO, Collateralized Debt Obligations, obligaciones de deuda colateralizada, CDS, Credit Defaut Swaps, cambio de riesgo de crédito...

32 Juan Antonio Melé, Dinero y conciencia (2009), pp. 41 y 42.

33 En Estados Unidos las hipotecas recaen sobre la vivienda, no sobre las personas, por lo que basta con devolver las llaves de la vivienda e irse a vivir de alquiler, lo que llamaron el jingle mail o correo tintineante (Carlos Salas, o. c., p. 121). En países como el nuestro la hipoteca puede producir el hecho de que el que no pueda pagarla deba dejar la vivienda y continuar endeudado en la medida de el precio de la misma haya descendido y sea insuficiente para cubrir el resto del crédito. Es por lo que aparecen anuncios de regalos de pisos con la condición de hacerse cargo de la hipoteca (Carlos Salas, o. c., capítulo 3, pp. 43 ss.). 
mer lugar en las sociedades hipotecarias estadounidenses Freddie Mac y Fannie Mae y el banco de inversiones Bear Sterns con dos fondos llenos de hipotecas «basura» con valor nulo reconocido.

En Europa, por su parte, ese verano de 2007 el banco británico Northern Rock no encontraba dinero entre los bancos por desconfianza, y el francés BNP Paribas suspendía los reembolsos de tres fondos ${ }^{34}$.

Si quedaba alguna duda acerca de lo que estaba sucediendo, la caída de Lehman Brothers a mediados de septiembre de 2008 vendría a dejar claro que la crisis financiera mundial había sido inaugurada oficialmente.

Fue, como señala Cazorla Prieto, el despertar del sueño de la prosperidad permanente:

Parecía para muchos que los ciclos económicos habían pasado a la historia y que una tendencia de sucesivos e imparables mejoramientos económicos constituían el signo de los tiempos. Enormes beneficios empresariales, paro arrinconado, Bolsa por las nubes, inflación bastante controlada, crédito para todos con garantías y casi sin garantías y por cuantías impensables, consumo desenfrenado y al alcance de casi todo el mundo que se quisiera apuntar a su rueda imparable, crecimiento sustancial del producto interior bruto, déficits presupuestarios controlados y, en algunos casos, aparición del casi mito del superávit presupuestario ... el cielo de la opulencia parecía cada vez más cercano ${ }^{35}$.

No es que nadie se hubiera dado cuenta, pero la generalidad no habíamos aprendido de la historia.

Carlos Salas cita a los «agoreros» a los que nadie escuchó: Armando Falcón, Michel Hudson, Luis Garicano, Guillermo de la Dehesa, y Rafael Pampillón ${ }^{36}$. Ignacio Ramonet, a dos estadounidenses, Nouriel Rubini y Paul Krugman ${ }^{37}$.

Con la crisis financiera y el fin de la burbuja inmobiliaria llegaron las ayudas al sistema financiero y a otros sectores a base de aumentar el déficit público y la deuda, la desconfianza de los bancos y la falta de crédito, la caída de las bolsas, cierres de empresas, descenso del producto interior bruto, desempleo, descenso del consumo...

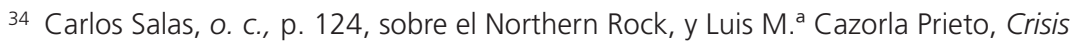
económica y transformación del Estado (2009), p. 25, citando a Krugman, The return of depression on economics and the crisis of 2008 (2009), p. 165, sobre BNP Paribas.

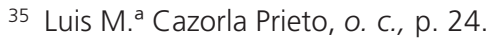

36 Carlos Salas, O. c., pp. 193 a 209.

37 Ignacio Ramonet, o. c., p. 86. 


\section{Elementos para interpretar la crisis}

Algunos autores creen que esta crisis no es sino un síntoma de una crisis global del propio sistema: «La crisis no es un árbol decrépito, aislado y suprimible, en medio de un bosque sano, sino que es el mismo bosque lo que está ya agotado», dice José Luis Sampedro apuntando a la decadencia del capitalismo ${ }^{38}$.

En el mismo sentido, Ignacio Ramonet considera que más que una crisis se trata de una revolución, un giro copernicano en el ámbito financiero similar a lo que la caída del Muro de Berlín significó en el ámbito geopolítico 39 .

En sentido contrario otros autores se oponen a esta consideración. Carlos Rodríguez Braun y Juan Ramón Rallo señalan que antes de la crisis «... se dejó de hablar del capitalismo, nombre que fue reemplazado por el de globalización, que en realidad significaba lo mismo, porque se achacó a la globalización unas perversiones similares a las capitalistas. El hecho de que se empleara un nuevo término quizá tenga que ver con la inmediatez de la implosión de la URSS, que tornaba ridícula la condena del capitalismo dados los resultados visibles e incuestionables del socialismo real. El paso del tiempo y una nueva perturbación económica autorizaron a los bienpensantes a archivar la globalización y a volver a agitar el fantasma siniestro con su nombre primigenio. Así, ahora no se habla de crisis de la globalización, sino de crisis del capitalismo», y argumentan contra la desregulación y las privatizaciones llevadas a cabo para resaltar el refuerzo del papel del sector público ${ }^{40}$.

También Juan Tugores, en referencia a Giulio Sapelli, habla del «retorno a un auténtico liberalismo... que huya tanto, por una parte, de la interesada "captura" a que han sometido las ideas liberales los apóstoles de unas desregulaciones y comportamientos tan faltos de sentido ético como de solvencia económica, como, por otro lado, de quienes tratan de aprovechar la ocasión para llevar el péndulo al extremo aparentemente opuesto pero que, pese a escudarse en retóricas socialistas, pueden estar conformando un "neopatrimonialismo" que suponga un retroceso histórico... $»^{41}$. Y Giulio Sapelli se refiere a ello reivindicando «una sociedad libre y abierta. Libre de aquellas incrustaciones burocrá-

38 José Luis Sampedro en la «Apertura: el árbol y el bosque» del libro de Rolando Astarita, El capitalismo roto: anatomía de la crisis económica (2009), p. 8.

39 Ignacio Ramonet, o. c., pp. 19 y 20.

40 Carlos Rodríguez Braun y Juan Ramón Rallo, Una crisis y cinco errores (2009), pp. 20-21 ss.

41 Juan Tugores Ques, en el prólogo al libro de Giulio Sapelli, Crac planetario (2009), p. 11. 
ticas y corporativas que oponen a la transparencia informativa la oscuridad organizativa y clientelar.... Abierta porque permite el recambio de las élites y de las clases dirigentes...» y termina por considerar que todo va en la dirección contraria ${ }^{42}$.

Más allá de las ideologías y el debate sobre las interpretaciones de las mismas, debemos destacar algunos elementos que puedan ayudar a comprender esta crisis y a prevenir la siguiente.

Seguiré en este punto los pasos de Francisco González, presidente del Banco BBVA, que advierte que no se trata de cosas exclusivas sino comunes en las crisis financieras:

... en muchas instituciones financieras se han cometido errores graves en el análisis y el control del riesgo que se han traducido en apalancamientos a todas luces excesivos. Han primado la codicia y el afán de obtener grandes beneficios en muy poco tiempo... ${ }^{43}$.

Se trata de la actuación ortodoxa tan recomendable a las instituciones financieras. Al margen de la misma se concedían créditos por más del $100 \%$ del valor, sin suficientes garantías, en base a una burbuja... «Multitud de consultores maniobraron al margen de la ética de la fidelidad al trabajo y a la empresa centrándose exclusivamente en su propio enriquecimiento inmediato» ${ }^{44}$. Dirigentes que cobraban por objetivos, intermediarios en la colocación de hipotecas, agencias de rating concediendo valoraciones exageradas mediante pago de la parte interesada, instituciones creando instrumentos financieros para desviar riesgos, arreglar su contabilidad, y obtener más beneficio... «... el actual crack planetario replantea el problema de una ética (individual y colectiva) a la cual nadie parece ya darle importancia alguna, puesto que ha sido sustituida por una inexistente y mistificadora ética de los negocios» ${ }^{45}$, siendo que, como indica Leopoldo Abadía, la ética es una y objetiva ${ }^{46}$.

Esto, que algunos otros llaman codicia y avaricia ${ }^{47}$, no sólo está presente en el lado de las instituciones y sus directivos, sino también entre las economías domésticas, los consumidores, que están dispuestos a

42 Giulio Sapelli, o. c., p. 51.

43 Francisco González, "La dimensión compleja de la globalización y la crisis financiera», en Las múltiples caras de la globalización (2009), p. 19.

44 Giulio Sapelli, o. c., p. 43.

45 Giuseppe de Lucia Lumeno, «Epílogo: Un capitalismo sin héroes», en Giulio SapeIli, o. c., p. 106.

46 Leopoldo Abadía, o. c., pp. 133 ss.

47 Carlos Sala habla de codicia, o. c., pp. 16 y 285; Oriol Amat, de envidia, ambición y soberbia que conducen a una ceguera..., o. c., pp. 30 y 31. Pérdida del sentido de los 
endeudarse más allá de sus posibilidades, a consumir sin límite, y que desean enriquecerse sin atender las indicaciones del sentido común.

"Simultáneamente, señala Francisco González, ha habido fallos graves en la regulación y la supervisión de las entidades financieras». Es decir que no han saltado las alarmas a pesar del enorme apalancamiento, del uso de instrumentos poco ortodoxos, y la loca carrera ha continuado en un vehículo sin frenos; «... debería haber sido evidente, continúa, que un largo periodo de tipos de interés extraordinariamente bajos, crecimiento rapidísimo de la liquidez y acumulación de desequilibrios de la balanza de pagos conduciría en un momento $u$ otro a problemas muy graves» ${ }^{48}$.

Ya hemos hecho una referencia a las pocas voces que anunciaron el camino de la crisis, lo que significa que empresas, gobiernos, instituciones, no vieron lo evidente.

Salas destaca la inacción del Fondo Monetario Internacional y del Banco Mundial. El entonces director general del Fondo, Rodrigo Rato, poco antes de dejar el puesto, en otoño de 2007, calificó la crisis como «manejable», y su sucesor, Dominique Strauss-Khan, negó primero la importancia de la crisis para meses después afirmar justamente lo contrario ${ }^{49}$. Esto, por sí sólo, considera Juan Velarde citando a los «viejos maestros», debería haber bastado como anuncio de la crisis que iba a llegar ${ }^{50}$.

Los desequilibrios de las balanzas de pagos, a los que se hace referencia, conducirían a la situación paradójica de que, en expresión de Alberto Recarte, los pobres financian a los ricos ${ }^{51}$, entendiendo por pobres a las economías emergentes, que financiaban el déficit de la balanza de los países a los que dirigían sus exportaciones.

El elemento diferencial de esta crisis «el altísimo grado de internacionalización (globalización) de la industria financiera, que se tradujo, entre otras cosas, en la elevada exposición de muchos bancos en todo el mundo a un conjunto de activos que resultaron altamente tóxicos» ${ }^{52}$.

"La crisis financiera de un país, dice Guillermo de la Dehesa, tiende a propagarse a otro como la peste bubónica» ${ }^{53}$. Es el efecto de la globalización que actúa tanto para lo bueno como para lo malo.

límites, falta de prudencia, de mesura, de austeridad, de discreción, de proporcionalidad... en Luis M. ${ }^{a}$ Cazorla Prieto, o. c., pp. 29 y 31.

48 Francisco González, o. c., p. 19.

49 Carlos Salas, O. C., pp. 174 y 175.

50 Juan Velarde Fuentes, «Crisis económica española: un juicio de responsabilidades», en Boletín de Doctrina Social de la Iglesia, n. ${ }^{\circ} 1$ (2009), p. 9.

51 Alberto Recarte, El informe Recarte (2009), pp. 80 ss.

52 Francisco González, o. c., p. 20.

53 Guillermo de la Dehesa, "The role of financial markets in self-fulfillment and contagion of financial crises», documento citado por Carlos Salas, o. c., p. 320. 


\section{¿Qué hacer de cara al futuro?}

Las respuestas inmediatas de dotación de liquidez y de garantías, reducción del tipo de interés, y todas sus consecuencias de déficit público, etc., ya se han dado, a pesar de no ser del agrado de todos, sobre todo teniendo en cuenta el mal uso que se ha hecho en algunas ocasiones de las ayudas recibidas, «... algunas de ellas fueron utilizadas de la forma más perversa que uno pudiera imaginar: ejecutivos de Citibank se compraron un avión a reacción» ${ }^{54}$.

Ahora tratamos de mirar un poco más lejos, de ver si somos capaces de recordar, contra el recurso de reprimir las experiencias desagradables, a pesar del aviso de Galbraith de que «el desastre se olvida rápidamente» ${ }^{55}$.

Naturalmente las medidas a tomar difieren en función de la posición doctrinal de los autores. De esta forma unos recomiendan más regulación y control y presencia pública, y otros más liberalización de ciertos sectores y mercados, menos impuestos que permitan más ahorro y menos gasto público correspondiente ${ }^{56}$.

Quisiera fijarme más, en cambio, en dos ideas que formula Francisco González para el sector bancario, que se pueden generalizar al conjunto de la economía, y que conectan directamente con una situación que va más allá de ser un mero ajuste y que tiende a la recuperación de la confianza de las personas que se ha defraudado con los comportamientos que han conducido a la crisis actual: se trata de la innovación en los productos y servicios que han de satisfacer las necesidades de las personas, y, a mi entender sobre todo, de la gestión empresarial basada en principios y valores éticos ${ }^{57}$.

La importancia de la innovación en el contexto presente no ofrece ninguna duda, resulta "aceptada de forma universal en la actualidad y ante cualquier situación económica» ${ }^{58}$. No se puede dejar de lado sea cual sea la situación económica, y, por ello, tampoco en el contexto de

54 Carlos Salas, o. c., p. 142.

55 John Kenneth Galbraith, Breve historia de la euforia financiera (2008), citado por Luis M. ${ }^{\text {a }}$ Cazorla Prieto, o. c., p. 39.

56 Así, Carlos Rodriguez Braun y Juan Ramón Rallo, o. C., pp. 117 y 118. También la nueva obra de Leopoldo Abadía, La hora de los sensatos (2010), p. 188, si bien en ella se da más importancia a las conductas éticas de personas competentes y trabajadoras, honestas y sensatas.

57 Francisco González, o. c., pp. 21 y 22.

58 Alejandro Martínez Charterina, «Innovación y cooperativas», en Boletín de la Asociación Internacional de Derecho Cooperativo, n. ${ }^{\circ} 43$ (2009), p. 156. 
la crisis. Al contrario tiene que valorarse como esencial para la recuperación y el asentamiento futuros.

Los principios y valores éticos suponen, entre otras cosas, transparencia, prudencia, conciencia social y de sostenibilidad, atención a los stakeholders ${ }^{59}$, todo ello integrado en la gestión, y hacen volver la mirada a las ideas de balance social de los años setenta del pasado siglo y de responsabilidad social de los tiempos presentes.

A fin de cuentas la empresa no flota en el aire sino que está inmersa en una sociedad con la que interactúa. Y tanto desde dentro de la misma, los accionistas, los gerentes, los trabajadores, como desde fuera, los clientes, los proveedores, los financiadores, las Administraciones públicas, y los grupos sociales, partidos políticos, sindicatos y la sociedad civil a través de sus asociaciones, interactúan con la empresa y son fuente de colaboración o de conflicto. Y es en este contexto en el que los principios y los valores éticos ofrecen una garantía que confiere la confianza y seguridad necesarias para la estabilidad sostenida de estas relaciones.

Al mismo tiempo ha de considerarse seriamente el problema de la sostenibilidad. "El cambio climático, la creciente vulnerabilidad del agua, la inestabilidad de los precios de la energía y la crisis de los precios de los alimentos en 2008 ilustran el alcance mundial y los efectos en cascada de las presiones que ejercemos sobre los ecosistemas» ${ }^{60}$. $\mathrm{Y}$, en consecuencia, se pone en tela de juicio que el PIB sea el indicador más adecuado para medir el progreso, sentido en el que se han venido posicionando los premios Nobel de economía Joseph Stiglitz y Amartya Sen. Por lo menos sería preciso contar con un indicador social y otro medioambiental, que completara al PIB destacando los límites y dando sentido a la idea de progreso ${ }^{61}$.

Este enfoque exige, además, una visión a largo plazo, que contrasta con la visión a corto plazo del desarrollo económico que se ha puesto de manifiesto en la búsqueda del beneficio inmediato y la ausencia de medidas estructurales en la crisis actual ${ }^{62}$.

59 Francisco González, o. c., p. 22.

60 Emèrit Bono, «Efecto riqueza de la especulación, crisis económica y límites de las políticas ambientales», en Ciriec-España, n. ${ }^{\circ} 66$ (2009), p. 228.

61 Emérit Bono, o. c., p. 229, se refiere a un indicador de progreso genuino (IPG) y cita a Stiglitz. Se recoge como noticia en El Economista, miércoles 4 de noviembre de 2009, pp. 42 y 43.

62 Rodrigo Gouveia, «Combatir la crisis económica global con la cooperación del consumidor», en Cuadernos de Economía Social, n. ${ }^{\circ} 3$ (2009), p. 6. 


\section{Las cooperativas ante la crisis actual}

La Declaración de la Alianza Cooperativa Internacional sobre la identidad cooperativa define ésta como asociación de personas y empresa económica63:

Una cooperativa es una asociación autónoma de personas que se han unido de forma voluntaria para satisfacer sus necesidades y aspiraciones económicas, sociales y culturales en común mediante una empresa de propiedad conjunta y de gestión democrática.

Siendo las cooperativas, por tanto, empresas, reciben el impacto de la crisis económica, y ese impacto se extiende por la globalización, como sucede con cualquier otra empresa.

¿Como sucede con cualquier otra empresa? Más allá de las particularidades que puedan darse, con carácter general, se puede afirmar que «las cooperativas son más resistentes a las crisis que otras formas de empresa»64.

El mismo Mensaje de la Alianza Cooperativa Internacional en el Día Internacional de las Cooperativas que realiza la afirmación anterior señala la solidez de las mismas y cita expresamente a las cooperativas financieras, agrarias, de consumo y de trabajo asociado.

En relación a los bancos cooperativos y uniones de crédito Johnston Birchall y Lou Hammond Ketilson señalan en su informe a la OIT aumentos de sus activos y depósitos, del volumen de los préstamos, y del número de socios, mejores tipos de interés en relación con los de los competidores, mayor estabilidad medida a través de coeficientes de suficiencia de capital y de tasa de impagados, pocas pérdidas de inversiones y poca necesidad de ayuda pública65.

Respecto a las cooperativas de consumidores, Rodrigo Gouveia relata el esfuerzo de las cooperativas de Finlandia, Reino Unido e Italia para conseguir el éxito en época de crisis 66 .

63 ICA, Declaración de la Alianza Cooperativa Internacional sobre la identidad cooperativa (1996), p. 17.

64 Así comienza el Mensaje de la Alianza Cooperativa Internacional en el 87. Día Internacional de las Cooperativas de la $\mathrm{ACl}, 15 .^{\circ}$ Día Internacional de las Cooperativas de Naciones Unidas, celebrado el 4 de julio de 2009, titulado «Impulsando la recuperación global a través de las Cooperativas», en base al informe para la Organización Internacional del Trabajo de Johnston Birchall y Lou Hamond Ketilson (2009), acerca de la resistencia del modelo de la empresa cooperativa en tiempos de crisis, citado en la nota 1.

65 Johnston Birchall y Lou Hammond Ketilson, O. c., pp. 15 ss.

66 Rodrigo Gouveia, o. C., pp. 6 y 7 
Con relación a las cooperativas de trabajo, Javier Divar formula las razones que, con carácter general, invitan al fomento público de las cooperativas de trabajo en épocas de crisis económica, y Goio Hernando refiere las medidas concretas de las cooperativas de Mondragón (MCC) en el tiempo presente ${ }^{67}$.

¿Por qué las cooperativas se defienden mejor que otras empresas frente a la crisis? Por el modelo de empresa. De la definición de cooperativa recogemos que se trata de una asociación de personas al mismo tiempo que una empresa económica, son las mismas personas que desean satisfacer sus necesidades las que conforman la empresa destinada a facilitar esa satisfacción.

Lo social y lo económico. Se trata, por consiguiente, de anteponer el servicio al beneficio, la satisfacción de la necesidad compartida al interés individual. Esto hace, a modo de ejemplo, que las cooperativas de trabajo, en las que los socios son los trabajadores, antepongan el mantenimiento del empleo a cualquier otra pretensión, tanto en tiempo normal como en tiempo de crisis ${ }^{68}$.

Las cooperativas, además, en función de su propia identidad aspiran a alcanzar unos valores que constituyen su base:

Las cooperativas están basadas en los valores de la autoayuda, la autorresponsabilidad, la democracia, la igualdad, la equidad y la solidaridad. Siguiendo la tradición de sus fundadores, los socios cooperativos hacen suyos los valores éticos de la honestidad, la transparencia, la responsabilidad y la vocación sociales ${ }^{69}$.

Y para ello acomodan su conducta al cumplimiento de unos principios a través de los cuales ponen en prácticas sus valores. Estos principios son siete:

1. Adhesión voluntaria y abierta.

2. Gestión democrática por parte de los socios.

3. Participación económica de los socios.

4. Autonomía e independencia.

5. Educación, formación e información.

67 Javier Divar, «Crisis económica, cooperativismo e innovación», en Boletín de la Asociación Internacional de Derecho Cooperativo, n. ${ }^{\circ} 43$ (2009), pp. 200 ss.; Goio Hernando, "La crisis económica y su impacto en el marco de las relaciones laborales: la respuesta de las cooperativas como tercera vía», en Boletín de Estudios Económicos, n. ${ }^{\circ} 196$ (2009), pp. 188 ss.

68 Javier Divar, o.c., p. 201, y Goio Hernando, o. c., p. 188.

69 ICA, o. C., p. 17. 
6. Cooperación entre cooperativas.

7. Interés por la comunidad.

En las empresas cooperativas, por consiguiente, rige el llamado principio de puerta abierta, o de voluntariedad, que permite entrar y salir sin discriminación a los socios. Éstos gestionan la sociedad democráticamente, cada socio tiene un voto; es la persona y no su aportación al capital la que vota.

El tercer principio, de participación económica de los socios, se refiere a la aportación al capital de la sociedad, al interés limitado como retribución al capital, y al reparto de los excedentes (beneficios), que, en la medida que no se destinen a fortalecer la cooperativa con dotaciones de reservas, o a otra finalidad aprobada por los socios, se distribuirá entre ellos en función a las operaciones realizadas por cada uno, no en función del capital aportado.

Las cooperativas deben actuar de forma autónoma, con independencia de los poderes públicos. Valoran la educación, la llamada «regla de oro», que permite la comprensión de los elementos característicos y valiosos del modelo, la formación para llevar a cabo sus tareas de forma competente, y la información que facilite hacia dentro una correcta toma de decisiones, y hacia fuera la comprensión y extensión del modelo cooperativo.

El séptimo principio se enfoca precisamente a la consecución del desarrollo sostenible de la comunidad ${ }^{70}$.

Hemos considerado que se debe encarar el futuro desde la innovación constante y el ejercicio de unos principios y valores éticos que consideren también el problema de la sostenibilidad.

Desde esta perspectiva podemos decir que las cooperativas se encuentran en una posición inmejorable.

Las cooperativas «están especialmente bien situadas para afrontar el desafío de la innovación en nuestros días», concluíamos un trabajo sobre la materia hace unos meses, teniendo en cuenta la preocupación de estas empresas por las personas y la mejor satisfacción de sus necesidades ${ }^{71}$.

Los valores y principios cooperativos, que conforman la esencia de las cooperativas, constituyen unos buenos referentes éticos de con-

70 Los valores y principios cooperativos forman, junto con la definición de cooperativa, la Declaración de la Alianza Cooperativa Internacional sobre la Identidad Cooperativa, que fue aprobada en el XXXII Congreso de la A.C.I. celebrado en Manchester, en 1995, año del centenario de su fundación. Recogido en ICA, o. C., pp 17-19. Puede verse, también, Alejandro Martínez Charterina, «Los valores y los principios cooperativos», en Revista de Estudios Cooerativos, n. ${ }^{\circ} 61$ (1995).

71 Alejandro Martínez Charterina, «Innovación y cooperativas», o. c., pp. 156 y 157. 
ducta que hacen que las cooperativas miren más al largo plazo que al beneficio inmediato, y puedan reaccionar con cierta holgura en las situaciones críticas.

En efecto, las cooperativas pueden operar sin beneficio, al menos temporalmente, el capital puede quedar sin retribución y en las cooperativas en las que los socios son los trabajadores pueden acordar trabajar jornadas más largas por la misma retribución o recortar su retribución, teniendo en cuenta que se trata de decisiones acordadas democráticamente por los propios socios trabajadores.

En el caso concreto de las cooperativas de Mondragón, Goio Hermando enumera medidas tomadas hacia el interior de cooperativas tales como congelación y reducción de las retribuciones a los socios, ajustes de empleo, movilización de calendarios... que no difieren, en cuanto medidas que tratan de reducir el gasto, de las que puede realizar cualquier empresa no cooperativa, pero en cambio difieren en cuanto a la finalidad de esas medidas. "Se puede dar el caso, como estamos observando..., dice por referencia al modelo no cooperativo, ... de empresas en crisis que reducen sus plantillas a la vez que reparten beneficios entre sus accionistas, o acometen un ERE planteándose incrementos salariales por encima del 1\% (referente de la patronal para la negociación colectiva de 2009)» ${ }^{72}$.

Teniendo en cuenta que las cooperativas de Mondragón forman una corporación, se han previsto medidas corporativas para ayudar a las cooperativas declaradas en desempleo estructural, es decir, aquellas con un excedente de plantilla que afecte significativamente a su situación, que no puedan absorber por sí mismas, y que tenga una cuenta de resultados con pérdidas. Estas ayudas comprenden prestaciones por desempleo, indemnizaciones, prejubilaciones, reconversión profesional, y reubicaciones ${ }^{73}$.

Este tipo de medidas se enmarcan en el principio de intercooperación o de cooperación entre cooperativas, que supone la prolongación más allá de cada cooperativa de la esencia de la misma, el agrupamiento para conseguir un objetivo colectivo, y conecta especialmente con los valores de autoayuda y solidaridad, entendiendo la primera como vía de paso para alcanzar fácilmente la segunda ${ }^{74}$. Por ello, la colaboración de unas cooperativas con otras puede llevarse a cabo a tra-

72 Goio Hernando, o. c., p. 190.

73 Goio Hernando, o. C., pp. 192 ss.

74 La autoayuda, self-help, se entiende no sólo como ayúdate a ti mismo sino también como ayudaos unos a otros, y se prolonga en la solidaridad. Puede verse Alejandro Martínez Charterina, Análisis de la integración cooperativa (1990), pp. 16 a 18. 
vés de las diversas estructuras que forman el movimiento cooperativo, y puede extenderse de unos países a otros.

Finalmente, de la sostenibilidad se ocupa el séptimo principio cooperativo, de interés por la comunidad, que se formuló por vez primera en la revisión de los principios del Congreso de Manchester, al que nos hemos referido anteriormente.

La Declaración de la A.C.I. lo define de este modo:

Las cooperativas trabajan para conseguir el desarrollo sostenible de sus comunidades mediante políticas aprobadas por sus socios. ${ }^{75}$

El Informe que acompaña a la Declaración amplía un poco esta idea. Como los socios habitualmente pertenecen a un mismo lugar formando parte de la comunidad local, las cooperativas «tienen una responsabilidad especial para asegurar que se sostenga el desarrollo de sus comunidades, económica, social y culturalmente. Tienen una responsabilidad de trabajar... para la protección medioambiental de esas comunidades». Y termina por afirmar «No es un conjunto de responsabilidades que los socios puedan obviar» ${ }^{76}$.

Antes de que se formulara este séptimo principio las cooperativas habían experimentado con un balance social adaptado a su funcionamiento, que se ocupaba no sólo de sus implicaciones con los grupos con interés en la empresa, stakeholders, sino también examinaba el cumplimiento de los principios cooperativos en la marcha de la cooperativa, al que se denominó balance cooperativo. En la actualidad estas acciones se articulan a través de la denominada Responsabilidad Social Empresarial, a la que la Alianza Cooperativa Internacional dedicó su mensaje el año 2007, cuyo título era «Los principios y valores cooperativos para la Responsabilidad Social Empresarial».

La Alianza considera en este mensaje que el movimiento cooperativo ha sido pionero en el ejercicio de la Responsabilidad Social Empresarial: "Desde sus inicios, las cooperativas han tenido en cuenta que sus acciones afectan a la gran mayoría de sus miembros, incluidos los trabajadores, la comunidad y el entorno en el que operan». Y entiende que los valores cooperativos son garantía a largo plazo del ejercicio de esa Responsabilidad Social Empresarial77.

75 ICA, o. C., p. 19.

76 ICA, o. C., p. 65.

77 Mensaje de la Alianza Cooperativa Internacional en el 85. Día Internacional de las Cooperativas de la $\mathrm{ACl}, 13 .^{\circ}$ Día Internacional de las Cooperativas de Naciones Unidas, 7 de julio de 2007, titulado «Los principios y valores cooperativos para la Responsabilidad Social Empresarial». 
Y en el mensaje del año siguiente insiste en que «muchas cooperativas trabajan día a día para garantizar que son empresas sostenibles tanto en lo económico, como en lo social y en lo ambiental», y «hace un llamamiento a todos los cooperativistas del mundo para que refuercen sus actividades de promoción del desarrollo sostenible» ${ }^{78}$.

Esto queda refrendado por la comparación y el encaje de los principios cooperativos con los correspondientes de la Responsabilidad Social Empresarial propuestos por la Comisión Europea ${ }^{79}$, a saber:

- Naturaleza voluntaria.

- Transparencia y credibilidad.

- Focalización en las actividades que aporten un verdadero valor añadido.

- Enfoque equilibrado en los ámbitos económico, social y medioambiental, y en los intereses de los consumidores.

- Atención a las necesidades específicas de las PYMES.

- Respeto a los acuerdos internacionales, tales como normas de trabajo de la OIT, directrices de la OCDE, etc.

La comparación de estos principios, que llevan a cabo Server y Capó, les lleva a decir que «la propia naturaleza de las cooperativas conlleva un funcionamiento socialmente responsable» 80 .

En el mismo sentido, Arcas y Briones comparan los valores y principios de la Responsabilidad Social Empresarial, seleccionados a través del estudio de la doctrina, con los valores y principios cooperativos encontrando, también, un notable paralelismo ${ }^{81}$.

78 Mensaje de la Alianza Cooperativa Internacional en el 86. Día Internacional de las Cooperativas de la $\mathrm{ACl}, 14 .^{\circ}$ Día Internacional de las Cooperativas de Naciones Unidas, 5 de julio de 2008, titulado «Lucha contra el cambio climático a través de las cooperativas».

79 Resumen de "Communication from the European Commission of 2 July 2002 concerning corporate social responsibility: A business contribution to sustainable development».

80 Ricardo J. Server Izquierdo y Jordi Capó Vicedo, «La responsabilidad social empresarial en un contexto de crisis. Repercusión en las sociedades cooperativas», en CiriecEspaña, n. ${ }^{\circ} 65$ (2009), pp. 17 y 18.

81 Narciso Arcas Lario y Antonio Juan Briones Peñalver, «Responsabilidad social empresarial de las organizaciones de la Economía Social. Valoración de la misma en las empresas de la Región de Murcia», en Ciriec-España, n. 65 (2009), pp. 148 ss. 


\section{Conclusiones}

1. Las crisis forman parte de la economía y con frecuencia se hacen presentes. Las cooperativas son empresas a las que las crisis no resultan extrañas. Muchas veces han nacido en contextos de crisis, y se han enfrentado a ellas, a veces para sucumbir, y las más de las veces para salir fortalecidas a través de las oportunidades que también les ofrecen.

2. A pesar de la experiencia de las crisis que periódicamente nos acompañan, la actual parece haber cogido por sorpresa a casi todo el mundo. La generalidad no ha visto los signos de la crisis y, en consecuencia, no ha tomado ninguna medida para prevenirla.

3. En esta crisis, como en otras ocasiones, se ha generado una burbuja que ha estallado y llevado a una crisis financiera de alcance mundial. Esta extensión se ha facilitado por el empuje de la globalización, que se presenta como una nota característica diferenciadora de otras anteriores, al menos por la profundidad y el alcance de la misma en la actualidad.

4. En esta crisis se han apreciado importantes problemas de falta de ortodoxia en la realización de los negocios, así como de sentido ético en las conductas. Del mismo modo no se ha contado con la regulación adecuada ni con los controles mínimos, y, por todo ello, no se ha contado con la visión de lo que venía, y se han rechazado las advertencias y las señales.

5. Las cooperativas, asociación de personas y empresa económica al mismo tiempo, acomodan su actuación a los valores y principios cooperativos que constituyen su identidad. Si miramos hacia adelante desde la empresa y consideramos que una empresa con futuro tiene que ser capaz de innovar de forma constante, tiene que llevar a cabo una gestión basada en valores éticos y debe comportarse en el marco de la responsabilidad social empresarial, el modelo cooperativo ofrece claras ventajas porque tales consideraciones conectan con su propia naturaleza.

\section{Bibliografía}

AbAdía, Leopoldo: La crisis ninja y otros misterios de la economía actual, Espasa, Madrid, 2009.

ABADÍA, Leopoldo: La hora de los sensatos, Espasa, Madrid, 2010.

Amat, Oriol: Euforia y pánico, 3. ${ }^{a}$ ed., Profit, Barcelona, 2009.

ARCAS LaRIO, Narciso y BRIOnes Peñalver, Antonio Juan: «Responsabilidad social empresarial de las organizaciones de la Economía Social. Valoración de la 
misma en las empresas de la Región de Murcia», en Ciriec-España, Revista de economía pública, social y cooperativa, n. ${ }^{\circ} 65,2009$, pp. 143-161.

AstARITA, Rolando: El capitalismo roto: anatomía de la crisis económica, La linterna sorda, Madrid, 2009.

BAYON, Denis: Le commerce véridique et social de Michel-Marie Derrion. Lyon 1835-1838, Atelier de création libertaire, Lyon, 2002.

BIRCHALL, Johnston y HAMMOND KETILSON, LOU: Resilience of the cooperative business model in times of crisis, ILO, Geneva, 2009.

Bono, Emèrit: "Efecto riqueza de la especulación, crisis económica y límites de las políticas ambientales», en Ciriec-España, Revista de economía pública, social y cooperativa, n. ${ }^{\circ} 66,2009$, pp. 213-231.

CAmeron, Rondo: Historia económica mundial. Desde el Paleolítico hasta el presente, 3. ${ }^{a}$ ed., Alianza Editorial, Madrid, 2000.

Cazorla Prieto, Luis M. ${ }^{\text {a: }}$ Crisis económica y transformación del Estado, Aranzadi-Thomson Reuters, Cizur Menor, 2009.

«Communication from the European Commission of 2 July 2002 concerning corporate social responsibility: A business contribution to sustainable development». Resumen en http://europa.eu/legislation_summaries/ employment_and_social_policy/employment_rights_and_work_organisation/ n26034_en.htm

Divar GarteizaurrecoA, Javier: "Crisis económica, cooperativismo e innovación», en Boletín de la Asociación Internacional de Derecho Cooperativo, n. ${ }^{\circ}$ 43, Universidad de Deusto, Bilbao, 2009, pp. 193-214.

GonzÁlez, FrAncisco, «La dinámica compleja de la globalización y la crisis financiera», en Las múltiples caras de la globalización, BBVA, Madrid, 2009.

GOUVEIA, Rodrigo: «Combatir la crisis económica global con la cooperación del consumidor», en Cuadernos de Economía Social, n. ${ }^{\circ}$ 3, CEPES, Madrid, 2009, pp. 6-7.

HernANDo, Goio, "La crisis económica y su impacto en el marco de las relaciones laborales: la respuesta de las cooperativas como tercera vía», en Boletín de Estudios Económicos, n. ${ }^{\circ} 196$, Universidad Comercial de Deusto, Bilbao, 2009, pp. 179-197.

HolyoAKe, Georges Jacob: Historia de los pioneros de Rochdale, Intercoop, Buenos Aires, 1989.

ICA, Declaración de la Alianza Cooperativa Internacional sobre la identidad cooperativa, CSCE, Vitoria-Gasteiz, 1996.

La Economía Social en España 2008/2009, CEPES (Confederación empresarial española de la Economía Social), Madrid, 2009.

LAIDLAW, A.F.: «Las cooperativas en el año 2000», en Tribuna Cooperativa n. ${ }^{\circ}$ 44-45, CENEC, Zaragoza, 1982, pp. 11 a 125.

MACKAY, Charles: Memoirs of Extraordinary Popular Delusions and the Madness of Crowds, $2^{\text {nd }}$ edition, Offffice of the National Illustrated Library, London, 1852 (en http://www.econlib.org/library/Mackay/macEx3html).

Martínez Charterina, Alejandro: «Innovación y cooperativas», en Boletín de la Asociación Internacional de Derecho Cooperativo, n. ${ }^{\circ} 43$, Universidad de Deusto, Bilbao, 2009, pp. 135-157. 
Martínez Charterina, Alejandro: La integración cooperativa, Universidad de Deusto, Bilbao, 1990.

MARTínez ChARTERINA, Alejandro: «Los valores y los principios cooperativos», en Revista de Estudios Cooperativos-REVESCO, n. ${ }^{\circ}$ 61, AECOOP y Universidad Complutense, Madrid, 1995, pp. 35-45.

Melé, Juan Antonio: Dinero y conciencia, Plataforma Ed., Barcelona, 2009.

Mensaje de la Alianza Cooperativa Internacional 2007: Los principios y valores cooperativos para la Responsabilidad Social Empresarial. En www.ica.coop/ activities/idc/2007-idc-es.pdf

Mensaje de la Alianza Cooperativa Internacional 2008: Lucha contra el cambio climático a través de las cooperativas. En www.ica.coop/activities/idc/2008idc-es.pdf

Mensaje de la Alianza Cooperativa Internacional 2009: Impulsando la recuperación global a través de las cooperativas. En www.ica.coop/activities/ idc/2009-idc-es.pdf

OrmaeCheA, José María: La experiencia cooperativa de Mondragón, Grupo Cooperativo Mondragón, s.l., 1991.

RAMONET, Ignacio: La catástrofe perfecta, Icaria, Barcelona, 2009.

ReCARTE, Alberto: El informe Recarte 2009, 3. ${ }^{a}$ ed., La esfera de los libros, Madrid, 2009.

Rodríguez Braun, Carlos y Rallo, Juan Ramón: Una crisis y cinco errores, LID, Madrid, 2009.

SALAS, Carlos: La crisis contada a sus víctimas, Áltera, Barcelona, 2009.

SAPELLI, Giulio: Crack planetario, Gedisa, Barcelona, 2009.

SerVer IzQuieRDo, Ricardo J. y CAPÓ VICEDO, Jordi: «La responsabilidad social empresarial en un contexto de crisis. Repercusión en las sociedades cooperativas», en Ciriec-España, Revista de economía pública, social y cooperativa, n. ${ }^{\circ}$ 65, 2009, pp. 7-31.

VÁzquez de Prada, Valentín: Historia económica mundial, tomo II, 3. ${ }^{a}$ ed., Rialp, Madrid, 1970.

VelaRde Fuentes, Juan: «Crisis económica española: un juicio de responsabilidades», en Boletín de Doctrina Social de la Iglesia, n. ${ }^{\circ} 1$, Fundación Pablo VI, Madrid, 2009, pp. 9-11. 